\section{Terra brasilis em Terra Estrangeira: ensaio sobre identidade}

\section{RESUMO}

Este artigo traz uma análise do filme Terra Estrangeira ${ }^{1}$ examinando o tratamento dado à representação da identidade brasileira e abordando as relações entre centro e periferia, à luz do arcabouço teórico da crítica cultural contemporânea, sobretudo do conceito de cosmopolitismo. São observados, ainda, aspectos relacionados à organização das teritorialidades urbanas na obra, enquanto espaços de articulação das identidades no contemporâneo.

\begin{abstract}
In this paper the author examines the way Brazilian identify is constructed bythe film Terra Estrangeira, the centerperiphery relationship, through the theoretical concept of cosmopolitism. Aspects of urban territorialities in the film are also observed as means of articulating identities in contemporaneity.
\end{abstract}

PALAVRAS-CHAVE

- Representação (Representation)

- Identidade (Identity)

- Contemporâneo (Contemporarneity)

\section{Introdução}

Produzido em 1995 e dirigido pelos cineastas Walter Salles e Daniela Thomas, o filme Terra Estrangeira foi realizado em um momento especialmente crítico para a produção cinematográfica brasileira. Com o fim da EMBRAFILME ${ }^{2}$, produtores e cineastas partiram em busca de novas alternativas para viabilizar seus trabalhos e este movimento refletiu, sem sombra de dúvida, a intenção de continuar produzindo, derecuperar ofôlego edesengavetar projetos.

Terra Estrangeira ${ }^{3}$ não apenas nasce neste contexto como também traz em sua narrativa claras menções ao recente momento histórico pelo qual o Brasil havia passado. Trata-se, dessa forma, de uma obra de ficção com um forte tom documental, que revela aspectos complexos da realidade brasileira, e coloca em xeque arcaicas noções e representações de identidade social e cultural.

A clara intenção dos autores de representar um Brasil sem salvaguardá-lo, sem protegê-lo, propondo uma reflexão sobre o contemporâneo que não aponta para sínteses, nem para lugares seguros, confere ao filme maturidade e vigor. O Brasil representado em Terra Estrangeira (a) parece deslocado, distanciado de coordenadas geográficas, à deriva. Não é o país do Carnaval, do samba, onde facilmente nos reconhecíamos, ou nos esforçaríamos para. É um país que expulsa, rejeita, hostiliza e não esconde suas dissonâncias e fraturas.

A narrativa do filme propõe um diálogo entre nações que mantiveram uma relação bastante estreita até bem pouco tempo. De um lado, o Brasil, ex-colônia. De outro, Portugal, excolonizador. A abordagem dessa complexa interlocução no filme acaba por redimensionar, de forma contundente, a relação entre o centro e a periferia, trazendo à tona as tensões, negociações e utopias que permeiam este (novo) processo.

Esta análise, na verdade, aceita a provocação do filme e se propõe a, em um primeiro momento, examinar o tratamento dado à questão da identidade (brasileira, latinoamericana, periférica) abordando as relações 
entre centro e periferia, à luz, sobretudo, do conceito de cosmopolitismo. Em um segundo momento, trata dos aspectos referentes à representação dos espaços urbanos e territorialidades, relacionando-os, quando possível, à temática da identidade.

O que se pretende é, em poucas palavras, ver um Brasil através do filme. Algumas questões naturalmente indicam a trilha deste percurso, às quais tentaremos responder, mesmo que provisoriamente. Como o filme Terra Estrangeira articula a questão da identidade brasileira e da inserção do Brasil no contemporâneo? Que sinais desta articulação se fazem presentes se o fazem - na narrativa? De que maneira os grandes centros urbanos são representados? Seria Terra Estrangeira uma tentativa de afirmação de um Brasil, embora ainda periférico, (subalterno?), também cosmopolita?

\section{Terra brasilis}

Acaloradosdebatesteóricos,emtornodatemática da identidade, têm sido travados no âmbito das Ciências Sociais, motivados, sobretudo, pela necessidade (ou ansiedade) de dar conta de um contemporâneo extremamente complexo e, em alguns aspectos, ainda obscuro. Se, por um lado, tais debates tendem ao abandono de modelos, paradigmas e categorias, por outro, não parecem intimidar-se diante da, não tão eventual assim, impossibilidade de síntese. Evidentemente que essa ruptura provocou, em maior ou menor grau, desconfortos e até mesmo desilusões. Não apenas por ter colocado em xeque cristalizadas verdades, mas, principalmente, por ter destituído de privilégios e poderes discursos, práticas e métodos. Esta encruzilhada epistemológica e teórica talvez seja a principal marca das Ciências Sociais contemporâneas que, afastadas das grandes narrativas e soluções, começam a desenhar novos caminhos e a enfrentar, de uma outra maneira, velhos dilemas.

O problema da identidade consiste seguramente em um dos nossos mais velhos dilemas. Não nos cabe aqui inventariar os tratamentos e enfoques dados à questão ao longo de mais de um século, sob pena de nos desviarmos muito do percurso esboçado. Entretanto, defendemos a pertinência de rapidamente explorarmos algumas (velhas) idéias e noções sobre esse (velho) dilema, até como uma forma de melhor compreendermos as diferenças encontradas na crítica cultural contemporânea.

Um dos primeiros problemas que os cientistas sociais brasileiros buscaram resolver em fins do século XIX foi o da existência e características da brasilidade, que segundo eles se comporia de duas vertentes: um patrimônio cultural formado de elementos harmoniosos entre si, que se conservaria semelhante através do espaço e do tempo; e a partilha do patrimônio cultural pela grande maioria dos habitantes do país, em todas as camadas sociais. Tais elementos consistiriam em bens materiais (maneiras de viver) e espirituais (maneiras de pensar). A totalidade desse patrimônio cultural poderia apresentar diferenças através do tempo e do espaço; mas seriam diferenças superficiais, um núcleo central profundo persistiria igual a si mesmo pelas idades afora, em todos os níveis sociais e etnias (Queiroz, 1989, p. 30).

Não por acaso escolhemos como ponto de partida para este breve passeio um trecho do artigo Identidade Cultural, Identidade Nacional no Brasil, de autoria da antropóloga Maria Isaura Pereira de Queiroz ${ }^{4}$. O eixo do artigo reside na observação das diferenças entre o tratamento dado ao conceito de identidade cultural no Brasil e na Europa. No Brasil, a identidade cultural teria sido pensada quase sempre como sinônimo de identidade nacional, tendo adquirido, assim, um forte conteúdo ideológico. Mesmo conscientes da heterogeneidade dos traços culturais brasileiros, resultantes, sobretudo, da histórica miscigenação de etnias, uma expressiva parte dos estudiosos, do início do século XX, esforçavase por "encontrar os culpados" de tamanha "desarmonia" cultural, ou, em outras palavras, por localizar este núcleo central profundo que atravessaria tempos, espaços e níveis sociais. Embutida nesta delirante busca, estava a noção de progresso, profundamente relacionada, por sua vez, ao nascente processo de modernização brasileira e de modernidade. Raimundo Nina Rodrigues, considerado pioneiro na etnografia brasileira e na psicologia social, chegava a ponto de atribuir a esta heterogeneidade cultural e biológica a causa de todos os desajustes socioeconômicos, o que teria comprometido o desenvolvimento e a chegada do tão desejado progresso. Em todos os autores identificados 
com esta linha de pensamento parecia haver a intenção de uma superação (desta heterogeneidade) que conduzisse a um "estado civilizatório" alinhado com os moldes europeu, ocidental, branco, metropolitano. Prysthon aborda esta questão e amplia o escopo para a formação das identidades na América Latina:

As 'identidades nacionais' latinoamericanas estariam sempre, portanto, sob o signo da miscigenação, do hibridismo, do 'atraso'e, no mínimo, do descompasso (em relação à metrópole) (Prysthon, 2002, p. 19).

Descompasso, frustração, imobilidade, impossibilidade de afirmar uma cultura autóctone, os olhares sempre voltados para a grande referência de modernidade - a Europa. Seja para afirmá-la como indicação para um percurso latino-americano, brasileiro, seja como veremos adiante - para negá-la, o fato é que a interlocução sempre existiu. Movimentos de inclusão ou de exclusão de características, traços, fenômenos culturais alternaram-se, ou até ocorreram simultaneamente, mas nem de longe ignoraram o poder exercido pela matriz européia.

Entre as mais vigorosas reações a esta proposição da formação cultural do Brasil atrelada (para não dizermos subjugada, colonialismo cultural) a um centro europeu, destacam-se os trabalhos produzidos, por exemplo, na Semana de Arte Moderna de 1922. Este evento teria inaugurado não apenas novos formatos artísticos (literários, plásticos, etc.), mas, sobretudo, uma maneira profundamente diferenciada de pensar o Brasil, que não compreendia a sua diversidade cultural como fator de desintegração, atraso, pobreza. O Brasil que tudo devora, fundindo tradição e modernidade, instaurando, através de criativos arranjos, uma outra relação com o centro.

Seguramente o impacto deste evento na reflexão sobre o Brasil se faz sentir até os dias de hoje, quando a discussão sobre a identidade, mesmo que afastada de parâmetros como nação, classe social, Estado, comunidade e sociedade, faz-se presente.

O retorno à temática da identidade cultural brasileira e latino-americana assume, entretanto, outros contornos dados pela própria complexidade do contemporâneo, que não mais parece admitirfáceis contraposições, como local $x$ universal, periferia $x$ centro, colônia (cultural) $x$ metrópole. Marcado pela diluição das fronteiras geográficas, políticas, econômicas e, até mesmo, simbólicas, o contemporâneo vê-se diante de um frenético processo de fragmentação das identidades, de relações de poder inscritas não mais na oposição entre blocos hegemônicos, de um descentramento que, no mínimo, desestabiliza "ordens e progressos". A discussão sobre as identidades abandona, portanto, a ilusão de reunir sob a égide de um mesmo nome - Brasil - características culturais, sobretudo quando estas não mais se relacionam - se, um dia, o fizeram - a pertencimentos e filiações (étnicas, de gênero, sociais, etc.). Ousa, de outro lado, vasculhar nichos, fendas, entrelugares, múltiplas e sobrepostas temporalidades, espaços, papéis, discursos, representações e poéticas que apontam para a formação de um campo - simbólico, cultural - de forças com características controversas e percursos imprevisíveis. A articulação destes caminhos no contemporâneo tem sido amplamente trabalhada pela crítica cultural, o que pode ser notado na introdução do livro O Local da Cultura, de Homi Bhabha:

É o tropo dos nossos tempos colocar a questão da cultura na esfera do além. (...) O "além" não é nem um novo horizonte, nem um abandono do passado... Inícios e fins podem ser os mitos de sustentação dos anos no meio do século, mas neste fin de siècle, encontramos no momento de trânsito em que espaço e tempo se cruzam para produzir figuras complexas de diferença e identidade, passado e presente, interior e exterior, inclusão e exclusão. Isso porque há uma sensação de desorientação, um distúrbio de direção, no além: um movimento exploratório incessante (...) (Bhabha, 1998, p. 19).

Após esse breve passeio, voltamos ao objeto de nossa análise, o filme Terra Estrangeira, com um olhar atento não apenas aos traços de uma geografia mutante ou de identidades esvaecidas, mas, sobretudo, que ouse entrever aquilo que nos torna estrangeiros em nossa terra brasilis. Ou brasileiros, em Terra Estrangeira.

\section{Terra brasilis em Terra Estrangeira}

Desde seu lançamento, o filme Terra Estrangeira tem provocado interessantes discussões sobre 
a questão da identidade no contemporâneo. Parece, de fato, ter sido esta a intenção dos diretores, quando, inspirados em uma fotografia, decidiram realizar o projeto.

Pouco a pouco percebemos que a imagem inicial do cargueiro emborcado na areia era um emblema do exílio. Não mais o exílio político dos anos da ditadura, mas um novo, econômico, que vem transformando o Brasil dos anos noventa num país de emigração, pela primeira vez em quinhentos anos. Aqui surge a imagem da terra estrangeira como uma solução, também idealizada, para a ausência de perspectiva, de auto-imagem, de identidade (Carvalho, 1997, p. 13).

A narrativa do filme se desenvolve inicialmente em duas histórias paralelas. De um lado, Paco e sua mãe, vividos respectivamente pelos atores Fernando Alves Pinto e Laura Cardoso, convivem em um pequeno apartamento de São Paulo, anos noventa. Paco deseja mudanças em sua vida, enquanto sua mãe quer apenas voltar a San Sebastian, na Espanha, sua terra natal. Já neste momento, percebe-se uma intenção de movimento - no caso, de retorno - que se tornará constante ao longo de todo o filme. As razões que motivam a personagem de Laura Cardoso a desejar o retorno poderiam ser resumidas numa só: um profundo descontentamento com o contexto político e econômico brasileiro de então. Entretanto, nota-se, ainda, nesta vontade, um componente pessoal, afetivo. $O$ retorno às origens significando a volta ao familiar, ao confortável, ao ambiente não hostil, ao lugar onde cultura e identidade estariam supostamente preservadas ou poderiam ser resgatadas. Fotografias de família, que para Paco não parecem ter grande importância, são cuidadosamente guardadas por sua mãe, talvez como último refúgio, lembrança de uma terra estrangeira que habitava na personagem.

De outro lado, Alex, personagem vivido pela atriz Fernanda Torres, brasileira voluntariamente exilada em Lisboa e refém de um subemprego. Divide a vida com um saxofonista sonhador, Miguel, que, através de contrabandos, viabiliza sua inevitável existência, onde o consumo de cocaína tem um lugar reservado. Parceiros de exílio, Alex e Miguel vivem, contudo, experiências distintas. Ela administra um cotidiano difícil, angustiado, rejeita as contravenções de Miguel, tenta sobreviver, reconhece sua condição de estrangeira, torna-se cada vez mais consciente de seu sotaque, de sua brasilidade.

Miguel, por sua vez, desliza de um lado para o outro de Lisboa, compromete-se com a contravenção como única alternativa de mudança em sua vida. A dissonância entre Alex e Miguel tem fim quando ele é morto em uma operação de contrabando malsucedida. Daí por diante, Alex apenas se protege em uma fuga sem rumo, despindo-se do único documento que atestava sua identidade brasileira, o passaporte. Esvaziase, desgarra-se, não cogita retorno a lugar algum, segue.

No Brasil, Collor anuncia o confisco das poupanças. Paco submete-se a um teste em um teatro e esquece o texto, perdendo a oportunidade. Volta para casa e encontra sua mãe morta em frente ao televisor. Desesperase, retrai-se em um estado de profunda solidão e abandono. Pensa em fazer o percurso que sua mãe não tivera chance - de volta a San Sebastian, embora não disponha de recursos para tal. Cruzar o oceano de volta à Espanha torna-se seu único desejo que subitamente transformase em realidade quando, através de um furtivo encontro com um desconhecido, lgor, Paco é convidado a levar uma encomenda a Lisboa. Sem ter muito a perder ou deixar para trás, ele aceita e parte em direção ao velho continente. Os acontecimentos tomam novo rumo, quando Paco chega a Portugal. Instalado em um pequeno hotel, rota da operação de contrabando da qual participava, Paco aguarda o receptor (Miguel) que lhe faria o resto do pagamento pelo serviço, o que Ihe permitiria seguir para San Sebastian. Miguel, porém, fora assassinado. Paco "perambula" pela Lisboa velha, um flaneur pós-moderno, sem referências, que não é, nem representa, o papel de herói.

Finalmente a encomenda é resgatada no hotel e Paco readquire confiança, supondo que, após o pagamento do que lhe fora prometido, poderia seguir viagem. Entretanto, a encomenda não fora resgatada pelos contrabandistas, mas por Alex, em uma insana intenção de estagnar a operação que havia causado a morte de Miguel. Paco foge e, a partir de algumas pistas, procura Alex para tentar reverter a situação, reaver a encomenda e retomar seu projeto de ir para a Espanha.

Alex e Paco encontram-se. Fugitivos de uma mesma sinistra história, de uma mesma terra brasilis e estrangeira. Ao saber que Alex dera a encomenda - pedras preciosas escondidas 
em um violino - a uma pessoa na rua, Paco, acuado, desespera-se. Paco e Alex partem em direção à Espanha por estradas alternativas. A viagem, afirmativamente fuga, assume, neste momento, um forte tom poético, sugerindo talvez um recomeço para os personagens. Contudo, logo este clima dissipa-se, quando os foragidos são encontrados pelos contrabandistas. Paco é baleado, Alex consegue resgatá-lo e, numa desesperada tentativa de salvá-lo e salvar-se, rompe as fronteiras entre Portugal e Espanha. San Sebastian é agora o destino de Alex.

Embora o fio condutor do filme, do ponto de vista temático, seja a abordagem de uma ausência de referenciais, de identidade, de estreitas relações com sociedades e culturas contemporâneas, no Brasil ou em Portugal, há que se notar uma forte imagem destes dois países na obra. A aparente dicotomia entre as duas nações se desfaz na medida em que passamos a compreender as trajetórias de Paco e Alex como vorazes tentativas de articulação de duas instâncias-a periferia e o centro. Articulação que, na verdade, mostra-se complexa, pois nos remete a uma constante negociação simbólica entre cosmopolitismos e, de outro lado, experiências fortemente localizadas (mesmo que seja em forma de remotas lembranças ou de desejos, rapidamente abandonados, de resgate de referências pessoais e culturais). Sobre o conceito de cosmopolitismo, Bruce Robbins, em uma menção ao antropólogo James Clifford, nota que:

Cosmopolitans are not tourists, from whom they are likely to be mistaken, because 'tourists are not participants'. They are not exiles, because the exile's involvement with another culture has been "forced". (...) Cosmopolitans, like expatriates and exexpatriates, 'are people who have chosen to live abroad. They know that 'they can go home when it suits them' (Cheah e Robbins, 1998, p. 259)

Para Paco e Alex, o retorno (para casa, para o Brasil) é praticamente impossível. A suposta autonomia de movimentos de uma atitude cosmopolita encontra-se, na trama, imobilizada em uma realidade contemporânea hostil que, de umamaneira oudeoutra, parecesempreressituar os personagens em posições periféricas, mesmo quando fisicamente localizados em um grande centro europeu. Assim, a fuga do Brasil para a
Europa teria simbolizado não a ruptura com a identidade brasileira, periférica, latino-americana, mas, sobretudo, a inserção deste mesmo Brasil em outras periferias. No filme, Portugal é o país do fado e também dos angolanos segregados em uma Lisboa (multicultural?), dos brasileiros subempregados e dos portugueses periféricos em relação ao resto da Europa. "Local ideal para perder alguém, ou para perder-se a si próprio", diz um personagem - português - do filme.

O traço cosmopolita dos personagens, das razões de suas atitudes, de suas trajetórias e escolhas, pode ser percebido, portanto, quando relacionado a uma rede de outros discrepantes cosmopolitismos:

Instead of renouncing cosmopolitanism as a false universal, one can embrace it as an impulse to knowledge that is shared with others, a striving to transcend partiality that is itself partial, but no more so than the similar cognitive strivings of many diverse peoples. The world's particulars can now be recoded, in part at least, as the world's discrepant cosmopolitanisms (Cheah e Robbins, 1998, p. 262).

O jogo de poder que permeia a relação entre os discrepantes cosmopolitismos no filme aponta não para uma perspectiva multiculturalista (que tudo inclui), mas para sucessivas exclusões, representadas pela intensa movimentação de fuga dos personagens Paco e Alex. Eles fogem da impossibilidade de articulação de diferenças, da exaustão e impotência diante da necessidade de manutenção de identidades.

A única ação possível em Terra Estrangeira é a fuga, que não preserva núcleos centrais de cultura, ou brasilidades, e afirma um Brasil híbrido, controverso, de limites e fronteiras frágeis, onde a inscrição no mundo contemporâneo distanciase de referências ou filiações culturais (latinoamericanas, terceiro-mundistas) engessadas e redimensiona o "velho dilema" da identidade não em termos de atraso ou modernidade, periferia ou centro, mas de atraso e modernidade, periferia e centro. Terra Brasilis e/é Terra Estrangeira.

\section{A geografia do deslocamento: São Paulo e Lisboa}

Um dos mais interessantes relatos deste constante deslocamento no filme consiste exatamente 
na representação de duas territorialidades urbanas distintas. São Paulo é revelada não através de panoramas, mas de meticulosos enquadramentos de seus prédios, avenidas e viadutos. Fragmentos de uma metrópole, fotografados em preto-e-branco, em um quase sinistro jogo de luz e sombra, antecipam tensões e nos dão, freqüentemente, a impressão de estarmos vendo não uma cidade brasileira, latino-americana, mas um grande centro urbano qualquer. A arquitetura das cidades contemporâneas é poeticamente descrita por Nelson Brissac Peixoto:

A arquitetura e urbanismo contemporâneos possuem uma aeração. A cidade, armada por uma nova trama de vetores, acelera, se desloca. Um espaço complexo é instaurado pela justaposição desses dispositivos. Esse impulso provoca sucessivas defasagens e arritmias, coisas rateiam e param, outras são submetidas a uma força desagregadora. O tecido se esgarça, fraturas rasgam a cidade. Um estilhaçamento que converte a nebulosa urbana num amálgama de áreas desconectadas (Peixoto, 1998,p. 519).

A cidade de São Paulo em Terra Estrangeira parece assumir estas características, bastante de acordo, a propósito, com a intenção do filme: falar de pessoas, culturas e identidades também estilhaçadas. Paco, desorientado e sozinho, circula pelas ruas centrais da cidade, refugia-se sob um grande viaduto, divide com anônimos transeuntes a dor da perda de sua mãe. A cidade o ignora e transforma-se ela mesma em um préexílio. Até mesmo em seqüências passadas no interior do apartamento, através de uma janela onde Paco concentrado ensaia um texto, a cidade se insinua, como se estivesse afirmando a sua opressora presença e, ainda, subvertendo os tênues limites entre o público e o privado no contemporâneo.

Os becos, ruelas, telhados de Lisboa sugerem, de um lado, uma cidade aprisionada em um velho desenho urbanístico e, de outro, os meandros (ou entrelugares) onde a narrativa se desenvolve. Oportuno notarmos uma certa continuidade entre as representações de São Paulo e Lisboa, esta também enquadrada em pequenos planos. Em nenhum momento a cidade é acolhedora para os personagens, salvo em uma única seqüência em que Miguel e Alex observam de um mirante a paisagem e, alheios ao que ela representa - exclusão, solidão, exílio - fazem planos.

À medida que a trama se desenvolve, o exílio torna-se cada vez mais opressor, conduzindo, em determinado momento, Paco e Alex para fora dos limites da cidade. Lisboa é deixada para trás, no que parece ser uma (a última) tentativa de salvação. A geografia do deslocamento em Terra Estrangeira reproduz, sobretudo, a ausência de referências e/ou lugares seguros. Não há destinos certos, nem trajetórias redentoras. Todos os caminhos parecem conduzir a um só lugar: o desterro, o nãolugar. Mesmo San Sebastian, cidade que habitou o imaginário de tantos personagens, simbolizando a esperança de retorno, resgate e recomeço, não tem existência física no filme. Não passa de um projeto não realizado.

A representação das territorialidades em Terra Estrangeira coloca-se, assim, como uma metáfora de um deslocamento cultural. De identidades em crise que procuram compreender seus lugares no contemporâneo, mesmo que isso signifique o abandono de velhas certezas e impressões. O vigor do filme pode ser atribuído, entre outras razões, à lúcida intenção de refletir e representar um país situado entre o moderno e o tradicional, o periférico e o central. Entre parênteses que nunca se fecham e provocam um olhar ora generoso, ora profundamente melancólico.

\section{Conclusão}

Alex Viany, crítico e cineasta, um dos mais freqüentes interlocutores dos diretores do Cinema Novo, em artigo escrito em 1965 e recentemente publicado, afirmava:

"Apesar da euforia produzida pelo surto do Cinema Novo, deve-se reconhecer que ainda não temos, do ponto de vista de uma cultura brasileira, um cinema nacional, tal como se fala de uma literatura nacional, por exemplo. Mas já temos, sem dúvida, espalhados em uns tantos filmes válidos (ou apenas parcialmente válidos), muitos dos elementos básicos que poderão conduzir, em futuro bem próximo, a um cinema verdadeiramente brasileiro" (Viany, 1999, p. 125).

Apesar do tom fortemente crítico e bastante irônico, nota-se uma crença na possibilidade de 
um cinema genuinamente nacional e, ainda, a indiscutível importância que este cinema teria enquanto elemento constitutivo da cultura brasileira. A contar pela profusão de tentativas e ações, na atualidade, voltadas para a "consolidação" do cinema nacional, poderíamos, sem sombra de dúvida, contradizer Viany (seguramente ele mesmo se encarregaria de rever sua posição, se estivesse vivo). De fato, só é passível de ser consolidado aquilo que já existe.

Entretanto, parece-nos que, antes de tentarmos pensar na existência ou subsistência de um cinema nacional, precisamos refletir sobre os traços dessa (suposta) brasilidade (representada). Na verdade, forma e conteúdo precisam ser observados em estreita relação, e, neste sentido, o filme Terra Estrangeira situase como um dos mais interessantes "surtos válidos" dos últimos anos. O debate sobre essa aparente desejada síntese do cinema brasileiro esbarra, assim, em questões contemporâneas mais amplas e complexas. Em 1960, cineastas e críticos culturais já se colocavam diante de controversas questões relativas, por exemplo, à representação de uma identidade cultural. $\mathrm{O}$ que teriam a dizer hoje os mesmos cineastas e críticos diante de um Brasil que não oferece qualquer possibilidade de síntese?

A análise do filme Terra Estrangeira trouxe-nos algumas conclusões que, embora assumidamente provisórias, apontam para a pertinência da reflexão e sugerem, ainda, alguns caminhos futuros. Voltando às questões colocadas na introdução deste artigo, poderíamos começar dizendo que a abordagem da temática da identidade cultural no filme é desenvolvida muito mais no sentido de demonstrar a complexidade da articulação da cultura no contemporâneo do que no sentido de advogar uma brasilidade. Não é um "olhar para dentro" que revela o Brasil, mas a sua inserção, enquanto país do Terceiro Mundo, latino-americano, no mundo. Evidentemente que tal relação não é, em si, original. Todavia, adquire um novo tom quando pensada não mais em função de antagonismos, mas de processos marcados por negociações. De maneira que Terra Estrangeira acaba por, em alguns momentos, exacerbar o jogo desigual de forças do contemporâneo, onde "heróis" e "bandidos" não podem ser facilmente identificados, onde opressores e oprimidos alternam-se em circunstâncias quase sempre hostis, onde cosmopolitas desistem de suas flanagens e rendem-se diante de um não tão admirável mundo novo.

A grande viagem ao contemporâneo proporcionada pelo filme dispensa mapas e pede um olhar disposto a ver não semelhanças, traços comuns (reconhecimento), mas, sobretudo, a ousar deparar-se com identidades de difícil compreensão, que, embora periféricas (em São Paulo ou em Lisboa), articulam, também, aspectos cosmopolitas. A rápida menção neste artigo à representação das territorialidades no filme tem um papel de imprimir uma certa "concretude"à complexidade do contemporâneo e da articulação das identidades. Isto é, passagens do filme foram indicadas no sentido de explorar a geografia do contemporâneo, suas imprecisões e deslocamentos.

A representação do Brasil em obras audiovisuais ficcionais tem revelado uma necessidade de compreensão do país. Não apenas de compreensão, mas, sobretudo, de (re)descoberta dos sinais de brasilidade. O cinema brasileiro percebe que representar e pensar o Brasil são partes de um mesmo processo, entremeado por angústias, dúvidas, tensões e, de outro lado, por atitudes corajosas, esperançosas, apaixonadas. Terra Estrangeira pode ser apontado, por fim, não como um fiel retrato de Brasil algum, mas como uma inspirada "invenção" de um Brasil contemporâneo que não dispõe de fáceis escapatórias e que constantemente nos convida à reflexão orientada para a articulação de complexidades e dissonâncias.

\section{Notas}

\section{Ficha Técnica:}

Direção: Walter Salles e Daniela Thomas

Elenco: Fernanda Torres (Alex); Fernando Alves Pinto (Paco) Luis Melo (lgor); Alexandre Borges (Miguel); Laura Cardoso (Manuela); João Lagarto (Pedro); Participação especial Tcheky Karyo (Kraft).

Roteiro original: Daniela Thomas, Marcos Berstein e Walter Salles

Diálogos adicionais: Millör Fernandes

Direção de fotografia: Walter Carvalho

Montagem: Walter Salles e Felipe Lacerda

Som direto: Geraldo Ribeiro

Música: José Miguel Wisnick

Direção de arte: Daniela Thomas

Figurino: Cristina Camargo 
Produção executiva: Flávio Tambellini

Co-produção Brasil: Paulo Dantas e Movie-Art

Co-produção Portugal: Antônio da Cunha Telles e Maria

João Mayer

Ano de produção: 1995

Duração: 102 minutos

Distribuição em vídeo: Riofilme e Sagres Vídeo

2 A EMBRAFILME foi extinta em 12 de setembro de 1990, através de um decreto do então presidente Fernando Collor de Mello. Interessante análise sobre a empresa no livro "Artes e Manhas da EMBRAFILME: Cinema Estatal Brasileiro em sua Época de Ouro (1977-1981)", do pesquisador e professor de cinema da UFF Tunico Amâncio. http:// jbonline.terra.com.br/jb/papel/cadernos/ideias/2002/04/26/ joride20020426019.html - Acesso em 28.06.02.

3 Farta quantidade de artigos e críticas sobre o filme e sua repercussão em platéias mundo afora foi produzida. Ver as indicações: http://www.uol.com.br/fsp/liustrad/fq131026. htm, http://www.uol.com.br/fsp/liustrad/fq270916.htm, http://www.uol.com.br/fsp/ilustrad/fq12039915.htm, http:// www.zaz.com.br/istoe/cultura/148328.htm, http://moviereviews.colossus.net/movies/f/foreign_land.html, http:// www.ufba.br/ revistao/03terra.html, http://www.matices. de/17/17ksalle.htm. - Acessos em 28.06.02.

4 Professora adjunta do programa de Pós-Graduação do Departamento de Sociologia (FFLCH) da USP.

\section{Referências}

BENJAMIN, Walter. Charles Baudelaire. Um lírico no auge do capitalismo. São Paulo: Brasiliense, 1989.

BHABHA, Homi. O local da cultura. Belo Horizonte: Editora da UFMG, 1998.

CARVALHO, Walter. Terra Estrangeira. Rio de Janeiro: Relume Dumará, 1997.

CHEAH, Pheng e ROBBINS, Bruce (eds.). Cosmopolitics. Thinking and Feeling Beyond the Nation. Minneapolis/London: University of Minnesota Press, 1998.

MOMPART, Josep Luís. "La configuración mediática de la ciudad contemporánea", IV Congresso de ALAIC, Recife, 12-16 de setembro de 1998.

MOREIRAS, Alberto. A exaustão das diferenças. A política dos estudos culturais latino-americanos. Belo Horizonte: Editora da UFMG, 2001.
ORTIZ, Renato. A moderna tradição brasileira. São Paulo: Brasiliense, 1988.

PEIXOTO, Nelson Brissac. Paisagens urbanas. São Paulo: SENAC/Marca D'Água, 1998.

PRYSTHON, Ângela. Cosmopolitismos periféricos: ensaios sobre modernidade, pós-modernidade e Estudos Culturais na América Latina. Recife: Bagaço, 2002.

QUEIROZ, Maria Isaura Pereira de. Identidade Cultural, Identidade Nacional no Brasil. In: Tempo Social; Ver. Sociologia da USP, São Paulo, 1989.

ROBBINS, Bruce. Comparative Cosmopolitanisms. In: ROBBINS, Bruce; CHEAH, Pheng (Org.). Cosmopolitics. Minneapolis: University of Minnesotta Press, 1998.

THOMAS, Daniela. Terra Estrangeira: roteiro. Rio de Janeiro: Rocco, 1996.

VIANY, Alex. O processo do Cinema Novo. [José Carlos Avellar, org.] Rio de Janeiro: Aeroplano, 1999. 